Research Article

\title{
Interval Nonprobabilistic Reliability Analysis for Ancient Landslide considering Strain-Softening Behavior: A Case Study
}

\author{
Zilong Zhou, Chenglong Lin, Xin Cai ${ }^{(D)}$, and Riyan Lan \\ School of Resources and Safety Engineering, Central South University, Changsha 410083, China \\ Correspondence should be addressed to Xin Cai; xincai@csu.edu.cn
}

Received 25 March 2020; Revised 14 June 2020; Accepted 15 June 2020; Published 15 July 2020

Academic Editor: Hailing Kong

Copyright (c) 2020 Zilong Zhou et al. This is an open access article distributed under the Creative Commons Attribution License, which permits unrestricted use, distribution, and reproduction in any medium, provided the original work is properly cited.

\begin{abstract}
Uncertainties in geotechnical parameters significantly affect the stability evaluation of an ancient landslide, especially when considering the strain-softening behavior. Due to the great difficulty in obtaining the probability density distribution of geoparameters, an interval nonprobability reliability analysis framework combined with numerical strain-softening constitutive relations was established in this paper. Interval variables were defined as the uncertain parameters in the strain-softening model. The interval nonprobabilistic reliability was defined as the minimum distance from the origin point to the failure surface in the standard normal space, which is the key index for describing the ability of a system to tolerate the variation of uncertain parameters. The proposed method was used to evaluate the reliability of Baishi ancient landslide. The parameter sensitivity analysis was also conducted. Through the proposed method, it is considered that Baishi ancient landslide is safe and stable, and the strain threshold $k_{r}$ is the dominant parameter. The results calculated by the proposed method agree well with the actual situation. This indicates the proposed method is more applicable than the traditional probability method when the data are scare.
\end{abstract}

\section{Introduction}

Considerable uncertainties exist in landslide engineering [1-5]. Traditional deterministic analysis cannot account for the uncertainty explicitly in most cases $[6,7]$. Overestimation or conservative estimation of stability is very common [8]. Therefore, the reliability analysis considering the effect of uncertainties should be proposed for exactly evaluating the landslide stability.

The reliability method has been developed for different fields since 1930s [9]. The reliability of engineering structure is defined as the ability to perform the predetermined function in the specified time under the specified conditions. In landslide engineering, the basic steps of reliability analysis are as follows $[9,10]$ : (1) determining the input variables; (2) determining the performance function of the limiting state; (3) calculating the reliability index. Great achievements have been made on landslide reliability calculation. The uncertainties in geomaterial properties and subsurface stratigraphic and other aspects of landslide engineering were well considered [11-13]. However, the strain-softening behavior, as a common characteristic in geomaterial deformation, was usually neglected $[14,15]$. It is necessary to consider the strain-softening behavior to evaluate the slope stability accurately [16-19].

Limited studies can be found to analyze the landslide reliability considering the strain-softening behavior. Terzaghi and Peck [20] firstly took notice of the strain-softening behavior of soil. Bishop [21] proposed the concept of progressive failure of slopes. Skempton [22] defined the average residual factor $R$ over a slip surface as the proportion of slip surface length over which the shear strength has reduced to a residual value. In a long time, residual factor $R$ has been the most commonly used parameter to describe the strainsoftening behavior in reliability analysis. Grivas and Chowdhury [23] firstly developed the probabilistic reliability analysis for strain-softening slopes. Stability factor $F_{s}$ was obtained by the limit equilibrium method with residual factor $R$, and a simple probabilistic reliability analysis was conducted under " $\varphi=0$ " assumption (ignoring the internal friction angle). Chowdhury et al. [24] considered the correlations between shear parameters. In recent years, Metya 
et al. [25] conducted a probabilistic reliability analysis based on the first -order reliability method; the performance function $\left(F_{s}-1\right)$ based on the Bishop simplified method was adapted to take strain-softening into account in terms of residual factor $R$. Bhattacharya et al. [26] regraded residual factor $R$ as a random variable, and the influence of $R$ was comprehensively analyzed and compared under different probability density distributions. These probabilistic reliability analyses can well describe the uncertainties in the strain-softening slope. However, these methods require the probability density distribution of uncertain parameters, which significantly affects the results of reliability evaluations. Usually, it is hard to obtain the adequate data describing the strain-softening behavior of landslide. The independent normal or log-normal distribution assumption can also cause some errors in the strain-softening relation. For examples, strength parameters may be negative based on normal distribution assumption. There are always some possibilities that the residual strength even exceeds the peak strength due to the long-tail curve in the independent normal or log-normal distribution assumption $\left(c_{r}>c_{p}\right.$, $\varphi_{r}>\varphi_{p}$, in which $c_{r}$ and $c_{p}$ are the peak and residual cohesion, respectively, and $\varphi_{r}$ and $\varphi_{p}$ are the peak and residual frictional angle respectively). In addition, the randomness of some uncertain parameters needs further discussion. Fortunately, the interval theory may provide a new strategy. This new idea was usually used in structure engineering [27-29]. Reliability was used to describe the ability of a system to tolerate the variation of uncertain parameters instead of failure probability. Interval values can better describe the uncertainties in stain-softening relations when the data are scare. The bounds of the interval value can also guarantee the correct relations between peak and residual strength $\left(c_{p}>c_{r}\right.$, $\left.\varphi_{p}>\varphi_{r}\right)$. Therefore, interval nonprobability reliability method has great application prospect in landslide engineering [30-32].

In this paper, an interval nonprobabilistic reliability analysis framework combined with numerical strain-softening constitutive relations was established. The proposed method requires only the boundary values instead of specific probability density distribution functions of uncertain parameters describing the strain-softening behavior, greatly decreasing the demanding for data. Nonprobabilistic reliability index $\eta$ instead of a deterministic safety factor $F_{s}$ or traditional probability of failure was used to describe the stability. The method was used to verify the stability of Baishi ancient landslide. Results of the proposed method were compared with the results of the traditional probabilistic method and the in situ investigation to prove the applicability. The sensitivity analysis was also discussed to make a reference for similar engineering.

\section{Methodology}

2.1. Interval Variables in Strain-Softening Model. To consider the uncertainties as well as the strain-softening behavior, numerical strain-softening constitutive model is commonly used [33]. In the simplified constitutive model, the strainsoftening behavior is characterized by five parameters: peak cohesion $c_{p}$, peak friction angle $\varphi_{p}$, residual cohesion $c_{r}$, residual friction angle $\varphi_{r}$, and the threshold parameter when strength reduces from peak to residual $k_{r}$.

The uncertainty of different parameters needs to be confirmed. As shown in Figure 1, $k_{r}$ was a parameter describing the malleability of strain-softening materials [33]. When $k_{r}$ increases from 0 to $\infty$, materials change from brittleness to malleability, and the strength of geomaterials changes from residual to peak state. Considering the noticeable malleability effect in soil deformation, $k_{r}$ is considered as a variable in this paper. $k_{r}$ is also greatly associated with the residual factor $R$ [22]; they are the cause and effect in negative correlation. Peak and residual shear strength $\left(c_{p}\right.$, $\varphi_{p}, c_{r}$, and $\left.\varphi_{r}\right)$ are the common parameters with great uncertainties describing the inherent quality of geomaterials $[15,26]$. Therefore, all these parameters in numerical strainsoftening constitutive model $\left(c_{p}, \varphi_{p}, c_{r}, \varphi_{r}\right.$, and $\left.k_{r}\right)$ are confirmed as interval variables to consider the uncertainties. It is noted that interval variables are assumed mutually independent.

2.2. Determination of Safety Factor $F_{s}$. The response interval of $F_{s}$ controlled by interval variables is obtained based on the numerical model in FLAC 3D. Each response of $F_{s}$ against each group of interval variables is calculated by the shear strength reduction (SSR) method, which is commonly used in landslide engineering $[34,35]$. The SSR method can truly represent stress-strain relations in the progressive failure process [33], thus very suitable for landslide with strainsoftening behavior. In this method, the safety factor is defined as the ratio of the actual shear strength to the reduced shear strength at failure (equations. (1) and (2)). Zhang et al. [36] extended this method to solve $F_{s}$ of a homogeneous slope with a strain-softening behavior:

$$
\begin{aligned}
& c_{f}^{\prime}=\frac{c^{\prime}}{F s}, \\
& \varphi_{f}^{\prime}=\arctan \left(\tan \frac{\varphi^{\prime}}{F_{s}}\right),
\end{aligned}
$$

where $F s$ is the safety factor; $c_{f}^{\prime}$ and $\varphi_{f}^{\prime}$ are the real strength parameters at failure; and $c^{\prime}$ and $\varphi^{\prime}$ are the original strength parameters.

Interval variables $c_{p}, \varphi_{p}, c_{r}, \varphi_{r}$, and $k_{r}$ are the input parameters. Specially, the strength reduction process is only conducted in the slip zones [37]. The accumulations and the bedrock layer remain unchanged with the Mohr-coulomb model. In other words, slip zones are considered as the overriding potential slip surface. The reason is that failures usually occur in local weaker materials firstly in the ancient landslide.

2.3. Performance Function $M$. Performance function $M$ presenting the limit state of system is established based on $F_{s}$ as

$$
M=F_{s}-1=g\left(c_{p}, \varphi_{p}, c_{r}, \varphi_{r}, k_{r}\right) .
$$




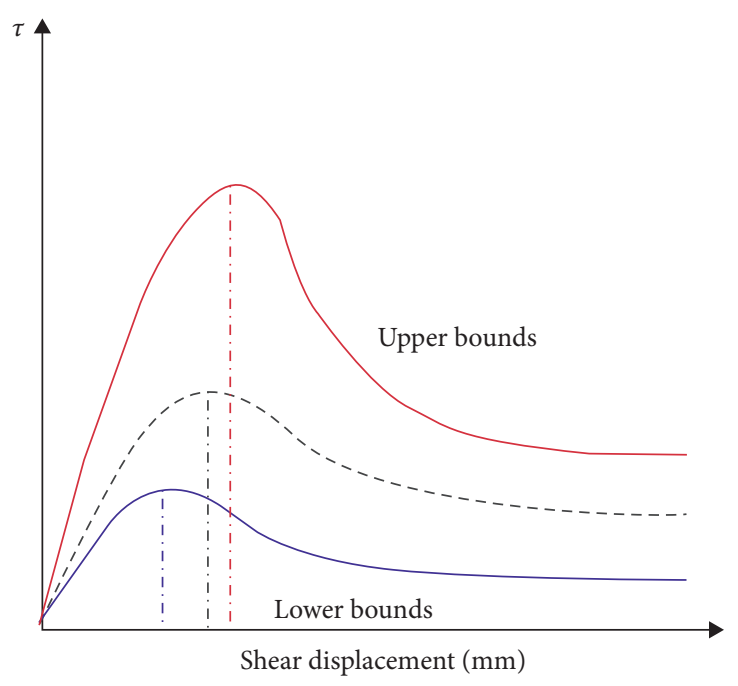

(a)

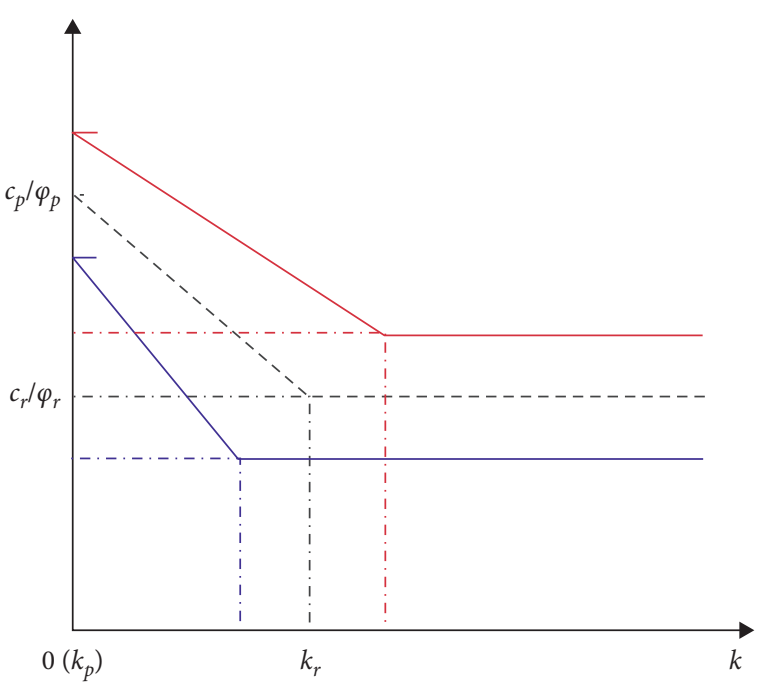

(b)

Figure 1: (a) Shear stress-displacement curves under a certain vertical stress. (b) Numerical strain-softening constitutive model (Conte et al.) [33].

However, numerical method cannot give an explicit relationship between $M$ and interval variables. In this paper, the explicit expression of $M$ was obtained by response surface fitting [38] via a series of deterministic tests. Usually, the explicit expression needs to be assumed in advance $[10,39,40]$. Some preliminary treatment is made to optimize the performance function in this paper. According to the expression obtained by the limit equilibrium method [26], $F_{s}$ can be written as

$$
\begin{aligned}
F_{s}= & R\left(\frac{c_{r}+\gamma z * \cos ^{2} i * \tan \varphi_{r}}{\gamma z * \sin i * \cos i}\right) \\
& +(1-R)\left(\frac{c_{p}+\gamma z * \cos ^{2} i * \tan \varphi_{p}}{\gamma z * \sin i * \cos i}\right) .
\end{aligned}
$$

For simplification, $F_{s}$ could be rewritten as

$$
F_{s}=w_{1} F_{p}+w_{2} F_{r}
$$

where $R$ is the residual factor, $w_{1}=1-R, w_{2}=R, F_{r}=\left(c_{r}+\right.$ $\left.\gamma z * \cos ^{2} i * \tan \varphi_{r}\right) /(\gamma z * \sin i * \cos i)$ is the residual safety factor, and $F_{p}=\left(c_{p}+\gamma z * \cos ^{2} i * \tan \varphi_{p}\right) /(\gamma z * \sin i *$ $\cos i)$ is the peak safety factor.

In equation (5), each subitem $\left(w_{1}, F_{p}, w_{2}, F_{r}\right)$ was assumed as a linear or quadratic polynomial for convenience. As introduced in Section 2.1, when $k_{r}=0$, materials are brittle, strength of whole slip surface are in residual state, and then $w_{1}=0, w_{2}=1$. Therefore, the assumed expressions of each subitems are written as

$$
\begin{aligned}
& F_{p}=a_{1}+a_{2} c_{p}+a_{3} \varphi_{p}+a_{4} \varphi_{p}^{2}, \\
& F_{r}=b_{1}+b_{2} c_{r}+b_{3} \varphi_{r}+b_{4} \varphi_{r}^{2},
\end{aligned}
$$

$$
\begin{aligned}
& w_{1}=c_{1} k_{r}+c_{2} k_{r}^{2}, \\
& w_{2}=1-\left(c_{1} k_{r}+c_{2} k_{r}^{2}\right),
\end{aligned}
$$

where $a_{1}, a_{2}, a_{3}, a_{4}, b_{1}, b_{2}, b_{3}, b_{4}, c_{1}, c_{2}$ are the undetermined coefficients.

Substituting equations (6)-(9) into equation (3), the performance function can be expressed as

$$
\begin{aligned}
M= & \left(c_{1} k_{r}+c_{2} k_{r}^{2}\right)\left(a_{1}+a_{2} c_{p}+a_{3} \varphi_{p}+a_{4} \varphi_{p}^{2}\right) \\
& +\left(1-c_{1} k_{r}-c_{2} k_{r}^{2}\right)\left(b_{1}+b_{2} c_{r}+b_{3} \varphi_{r}+b_{4} \varphi_{r}^{2}\right)-1 .
\end{aligned}
$$

After fitting a series of deterministic results $\left(\left(c_{p}, \varphi_{p}, c_{r}\right.\right.$, $\left.\left.\varphi_{r}, k_{r}\right), M\right)$, the explicit expression of $M$ in equation (10) can be obtained.

2.4. Reliability Analysis Based on Interval Theory. Interval nonprobability reliability index $\eta$, representing the ability of a system to tolerate the variation of uncertain parameters, is defined as the minimum distance between original point and failure surface in the standard normal space [27-29] (as shown in Figure 2).

For $\forall M=g\left(x_{1}, x_{2}, \ldots, x_{n}\right)$, where $M$ is the performance function, $\left(x_{1}, x_{2}, \ldots, x_{n}\right)$ are the controlling interval variables, there are $\forall x_{i} \in\left[x_{i}^{\min }, x_{i}^{\max }\right](i=1,2, \ldots, n)$, where $x_{i}^{\min }$ and $x_{i}^{\max }$ are the lower and upper bounds of $x_{i}$ respectively. Then, the performance function $M$ is also an interval $M=$ $\left[M^{\mathrm{min}}, M^{\mathrm{max}}\right]$ to response, where $M^{\mathrm{min}}$ and $M^{\mathrm{max}}$ are the lower and upper bounds of $M$, respectively. $M^{c}$ and $M^{r}$ are defined as the mean and radius of $M$, respectively (equations (11) and (12)). Then, the interval nonprobability reliability index $\eta$ is defined as in equation (13): 


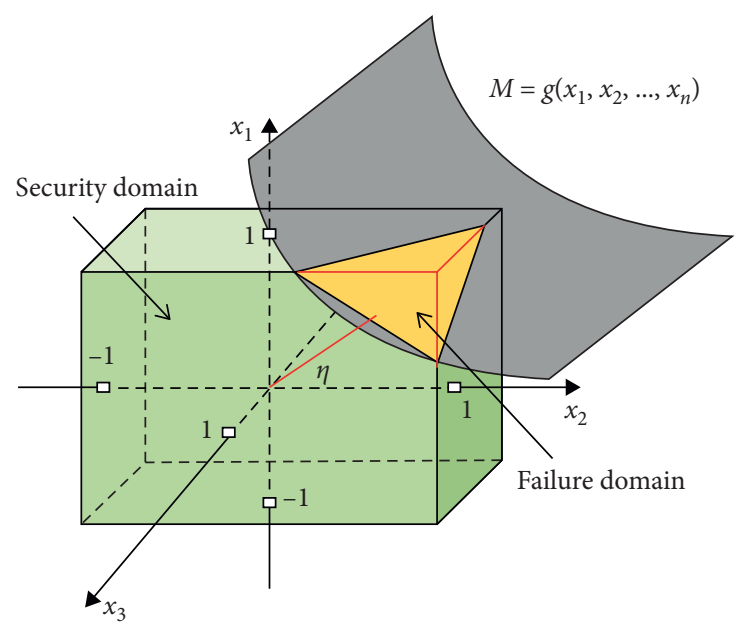

FIGURE 2: Schematic diagram of interval nonprobability reliability.

$$
\begin{aligned}
M^{c} & =\frac{1}{2}\left(M^{\min }+M^{\max }\right), \\
M^{r} & =\frac{1}{2}\left(M^{\max }-M^{\min }\right), \\
\eta & =\frac{M^{c}}{M^{r}},
\end{aligned}
$$

where $M=g\left(x_{1}, x_{2}, \ldots, x_{n}\right)=0$ is the failure plane, and this hypersurface divides the space into the failure domain and the security domain. When $M=g\left(x_{1}, x_{2}, \ldots, x_{n}\right)<0$, the system is in failure state and the opposite it is in safe state. According to equations (11)-(13), if $\eta>1$, then $\forall x_{i} \in\left[x_{i}^{\min }, x_{i}^{\max }\right](i=1,2, \ldots, n), M=g\left(x_{1}, x_{2}, \ldots, x_{n}\right)>0$, and the system is safe and reliable. If $\eta<1$, then $\forall x_{i} \in\left[x_{i}^{\min }, x_{i}^{\max }\right](i=1,2, \ldots, n), M=g\left(x_{1}, x_{2}, \ldots, x_{n}\right)<0$ and the system fails. If $-1 \leq \eta \leq 1$, then $\forall x_{i} \in\left[x_{i}^{\min }, x_{i}^{\max }\right]$ $(i=1, \quad 2, \quad \ldots, \quad n), \quad M=g\left(x_{1}, x_{2}, \ldots, x_{n}\right)<0 \quad$ or $M=g\left(x_{1}, x_{2}, \ldots, x_{n}\right)>0$ or $M=g\left(x_{1}, x_{2}, \ldots, x_{n}\right)=0$ are all possible. As a result, the system could be safe or in failure. And, the larger the value of $\eta$, the safer the system [32].

\section{Case Study: Baishi Ancient Landslide}

3.1. Geological Background. To verify the applicability of our reliability analysis method, we took a strain-softening landslide, i.e., Baishi ancient landslide, as an example. Baishi ancient landslide is located at the south mountains area in Guangxi province, China (Figure 3(a)). Geographic, geomorphic, elevation, and other information is shown in Figure 3(b). Geologically, Baishi landslide is an accumulated ancient landslide with obvious ancient slip bands. The geomaterial distribution could be described as three uneven layers: (1) argillaceous sandstone bedrock downmost, (2) slip bands with strain-softening behavior in-between, and (3) soil-gravel accumulations uppermost.

3.2. Parameter Collection. Some critical parameters used for simulation were collected from geological surveys or engineering experience as listed in Table 1.
3.3. Interval Variables and Numerical Model in Case Study. According to in situ data and engineering experience $[15,33,41]$, interval variables of Baishi ancient landslide are set in Table 2. Correlation relation of parameters $\left(c_{p}>c_{r}\right.$; $\left.\varphi_{p}>\varphi_{r}\right)$ in strain-softening constitutive is well presented.

The numerical model in FLAC 3D of Baishi ancient landslide is established on the real geological information. According to some preliminary computation and in situ surveys, profile A- $\mathrm{A}^{\prime}$ in Area $\mathrm{I}$ is chosen as the main research object (shown in Figure 4). In this model, the ancient slip zones are abstracted as a $2 \mathrm{~m}$ thick band. The mesh of slip zones is almost all quadrangles of $1 \mathrm{~m} \times 1 \mathrm{~m}$, and the grid division is enough for computation.

\section{Results and Discussion}

4.1. Stability Analysis. Table 3 presents some results of deterministic analysis of Baishi ancient landslide. Three examples are conducted. In example 1, safety factor $F_{s}$ is calculated in peak strength when the peak strength parameters $\left(c_{p}, \varphi_{p}\right)$ are set as the maximum, mean, and minimum values, respectively. In example 2 , safety factor $F_{s}$ is calculated in residual strength when the residual strength parameters $\left(c_{r}, \varphi_{r}\right)$ are set as the maximum, mean, and minimum values, respectively. In example 3, safety factor $F_{s}$ is calculated considering the strain-softening behavior when $k_{r}$ is set as the maximum, mean, and minimum values, respectively. In these three examples, all the parameters are set as mean values except for the assigned parameters. In examples 1 and 2, results are also calculated by the Spencer method to make a comparison with that by the SSR method.

Results in examples 1 and 2 indicate that, when $F_{s}$ is calculated only in peak or residual strength, uncertainties of shear strength parameters $\left(c_{p}, \varphi_{p} ; c_{r}, \varphi_{r}\right)$ can cause great differences. The values of $c_{p}, \varphi_{p}$ and $c_{r}, \varphi_{r}$ should be thus considered as variables. Results calculated by SSR and Spencer methods are in good agreement, which indicates that the numerical model and method in this paper are valid. Results in example 3 indicate that when $F_{s}$ is calculated considering the strain-softening behavior, the results are significantly influenced by the value of $k_{r}$. Also, $k_{r}$ is set as a variable. Moreover, calculation results of $F_{s}$ are 1.695, 1.095, and 1.414, respectively, 


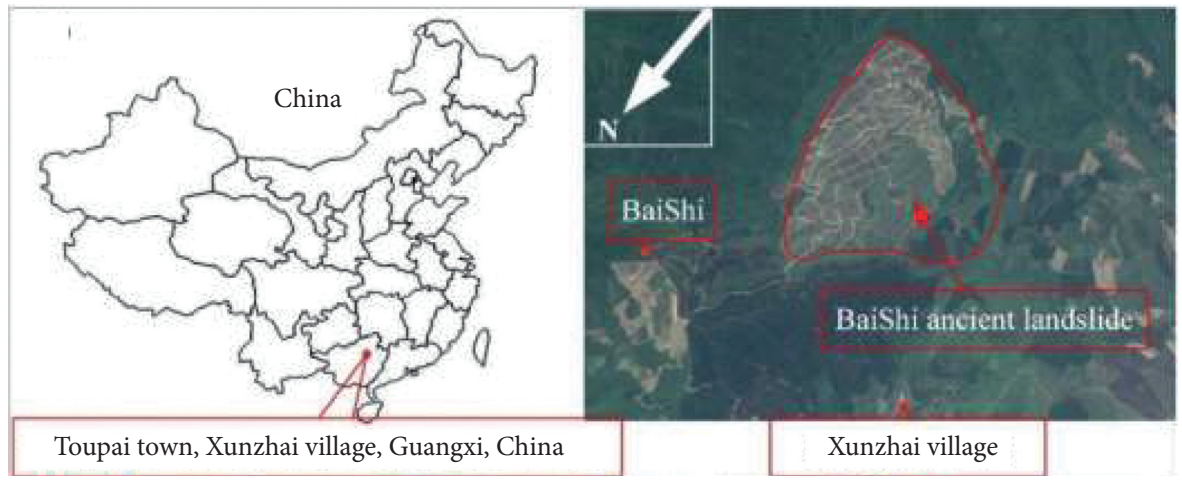

(a)

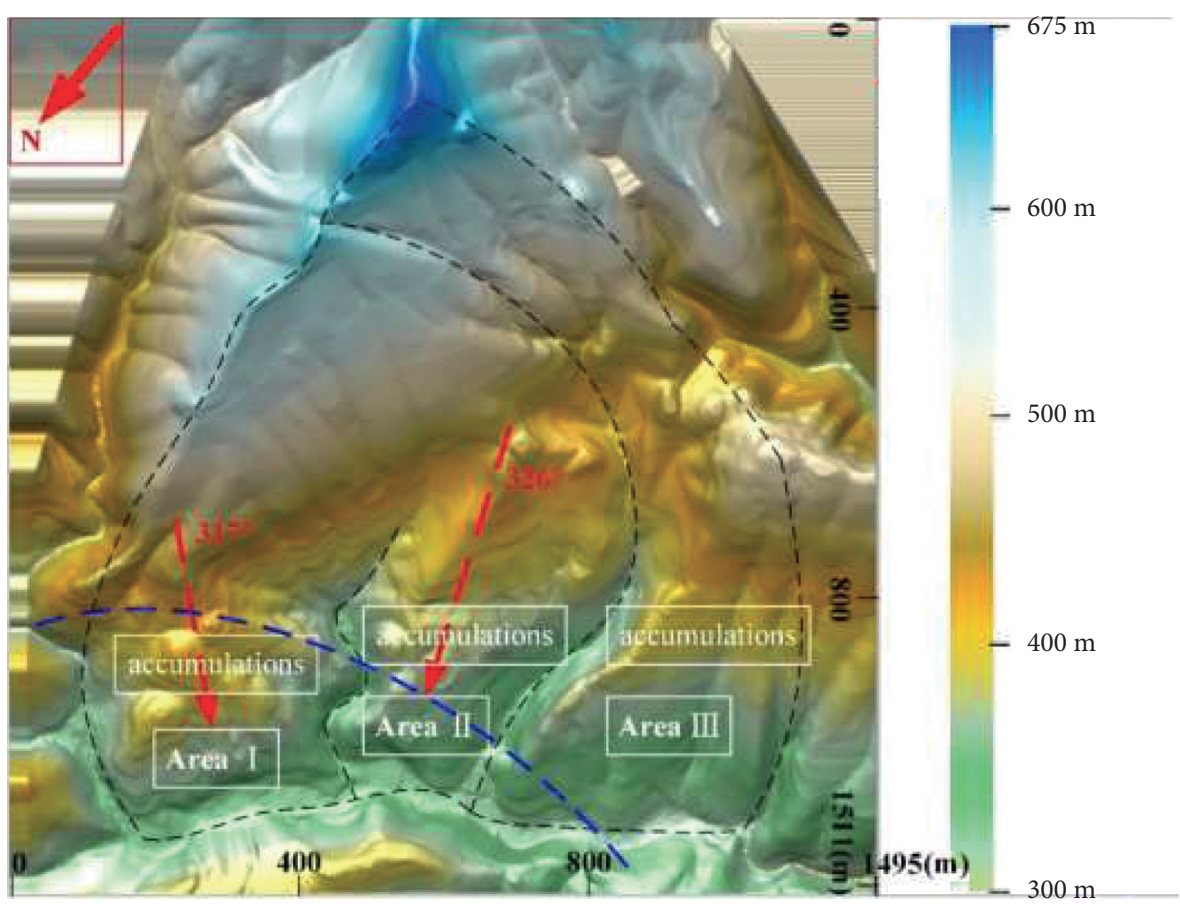

$\begin{array}{ll}\longrightarrow \text { North direction } & --- \text { Boundary } \\ -\rightarrow \text { Sliding direction } & --- \text { Planned road }\end{array}$

(b)

Figure 3: (a) Location and (b) digital elevation model of Baishi ancient landslide.

TABLe 1: Physical and mechanical parameters of Baishi ancient landslide.

\begin{tabular}{lccc}
\hline Item & Accumulations & Bedrock & Slip bands \\
\hline $\begin{array}{l}\text { Constitutive } \\
\text { relation }\end{array}$ & Mohr-Coulomb & Mohr-Coulomb & $\begin{array}{c}\text { Strain- } \\
\text { softening }\end{array}$ \\
$E(\mathrm{GPa})$ & 1 & 10 & 0.1 \\
$v$ & 0.3 & 0.3 & 0.3 \\
$\rho\left(\mathrm{kg} \cdot \mathrm{m}^{3}\right)$ & 1960 & 2130 & 2450 \\
$c(\mathrm{kPa})$ & 26 & 130 & - \\
$\varphi\left({ }^{\circ}\right)$ & 29 & 42 & - \\
$c_{p}(\mathrm{kPa})$ & - & - & $12.5 \sim 16.8$ \\
$\varphi_{p}\left({ }^{\circ}\right)$ & - & - & $17.9 \sim 24.7$ \\
$c_{r}(\mathrm{kPa})$ & - & - & $3.1 \sim 12.5$ \\
$\varphi_{r}\left({ }^{\circ}\right)$ & - & - & $10.6 \sim 17.9$ \\
\hline
\end{tabular}

Note: only the shear strength parameters of slip bands were collected in detail.
TABLE 2: Interval variables in the case study.

\begin{tabular}{lcc}
\hline Interval variables & Units & Range \\
\hline$c_{p}$ & $\mathrm{kPa}$ & {$[12.5,16.8]$} \\
$\varphi_{p}$ & $\circ$ & {$[17.9,24.7]$} \\
$c_{r}$ & $\mathrm{kPa}$ & {$[3.1,12.5]$} \\
$\varphi_{r}$ & $\circ$ & {$[10.6,17.9]$} \\
$k_{r}$ & - & {$[0,0.1]$} \\
\hline
\end{tabular}

Note: only the parameters of slip zones are considered with the strainsoftening behavior and abstracted as interval variables.

when parameters $\left(c_{p}, \varphi_{p} ; c_{r}, \varphi_{r}\right)$ are set as the mean value of peak strength and residual strength and in the case of considering the strain-softening behavior. Result indicates that the strain-softening behavior should be considered in the stability evaluation of Baishi ancient landslide. 

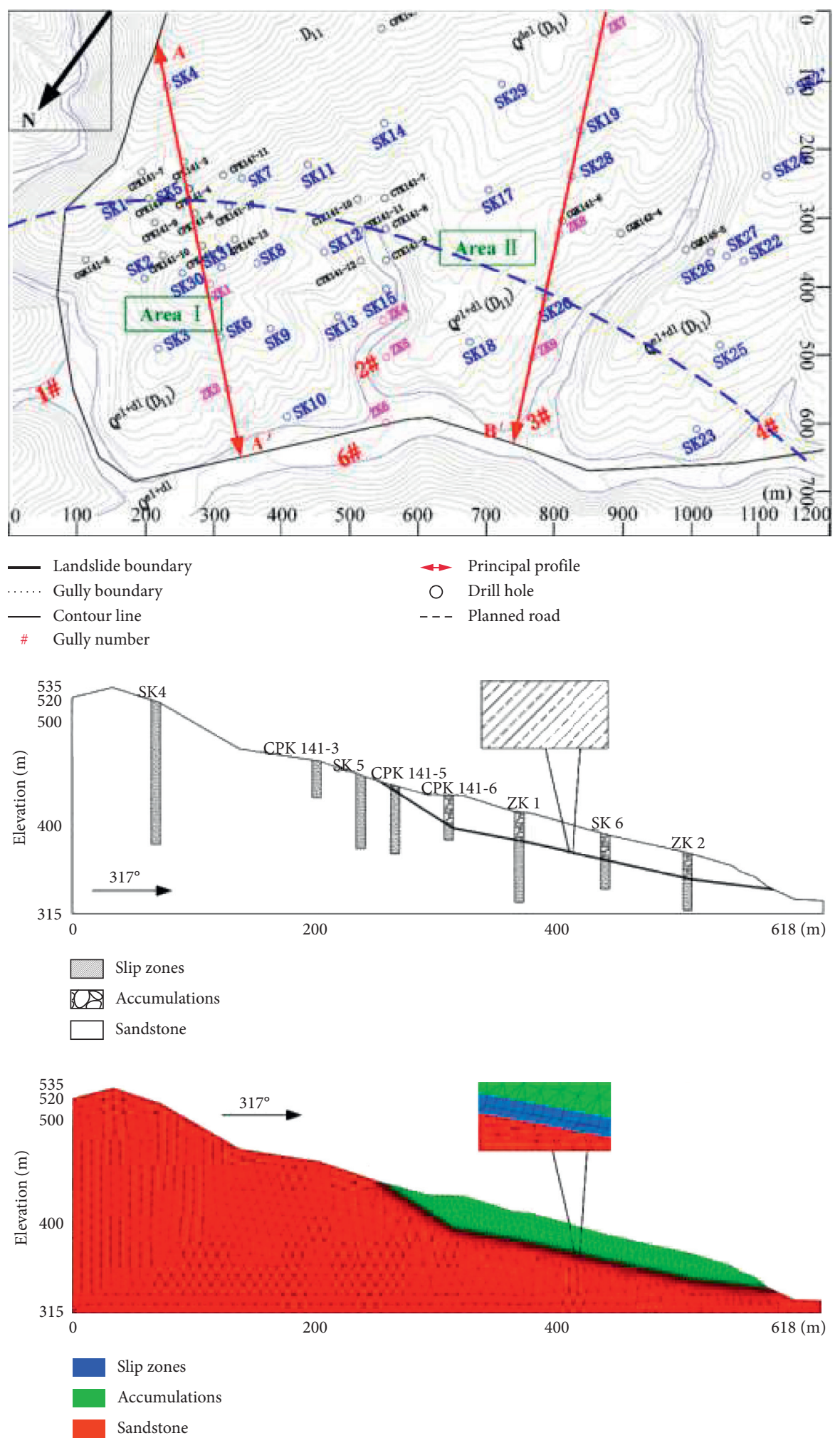

FIgURE 4: Geological information and numerical model of the case study.

\subsection{Performance Function Analysis}

4.2.1. Results of Performance Function. Table 4 presents some results of deterministic tests for fitting the performance function. The central composite design was used to conduct the deterministic stability computation. As shown in Table 3, numbers $1-32$ are the $2^{5}$ groups of two-level design of five variables $\left(c_{p}, \varphi_{p}, c_{r}, \varphi_{r}\right.$, and $\left.k_{r}\right)$; numbers $33-37$ are 5 groups of extension tests for nonlinear influence checkout; numbers 38-42 are 5 groups of random tests on the limited interval. 
TABLE 3: Comparison of $F_{s}$ considering three different strength states.

\begin{tabular}{|c|c|c|c|c|c|}
\hline Item & Vari & iable & $\begin{array}{c}F_{s} \\
(\mathrm{SSR})\end{array}$ & $\begin{array}{c}F_{s} \\
\text { (spencer) }\end{array}$ & $\begin{array}{c}\text { Relative errors } \\
(\%)\end{array}$ \\
\hline \multirow{3}{*}{ Example 1} & \multirow{3}{*}{$c_{p}, \varphi_{p}$} & Max. & 1.997 & 1.997 & 0.000 \\
\hline & & Mean & 1.695 & 1.698 & 0.177 \\
\hline & & Min. & 1.402 & 1.406 & 0.284 \\
\hline \multirow{3}{*}{ Example 2} & \multirow{3}{*}{$c_{r}, \varphi_{r}$} & Max. & 1.402 & 1.406 & 0.284 \\
\hline & & Mean & 1.095 & 1.092 & 0.274 \\
\hline & & Min. & 0.793 & 0.794 & 0.126 \\
\hline \multirow{3}{*}{ Example 3} & \multirow{3}{*}{$k_{r}$} & Max. & 1.535 & - & - \\
\hline & & Mean & 1.414 & - & - \\
\hline & & Min. & 1.097 & - & - \\
\hline
\end{tabular}

TABLE 4: Results of central composite design in FLAC 3D.

\begin{tabular}{lcccccc}
\hline Number & $c_{p}(\mathrm{kPa})$ & $\varphi_{p}\left({ }^{\circ}\right)$ & $c_{r}(\mathrm{kPa})$ & $\varphi_{r}\left({ }^{\circ}\right)$ & $k_{r}$ & $F_{s}$-FLAC $3 \mathrm{D}$ \\
\hline 1 & 16.80 & 24.70 & 12.50 & 17.90 & 0.00 & 1.408 \\
2 & 12.50 & 24.70 & 12.50 & 17.90 & 0.00 & 1.405 \\
3 & 16.80 & 17.90 & 12.50 & 17.90 & 0.00 & 1.408 \\
4 & 12.50 & 17.90 & 12.50 & 17.90 & 0.00 & 1.405 \\
5 & 16.80 & 24.70 & 3.10 & 17.90 & 0.00 & 1.364 \\
6 & 12.50 & 24.70 & 3.10 & 17.90 & 0.00 & 1.364 \\
7 & 16.80 & 17.90 & 3.10 & 17.90 & 0.00 & 1.364 \\
8 & 12.50 & 17.90 & 3.10 & 17.90 & 0.00 & 1.359 \\
9 & 16.80 & 24.70 & 12.50 & 10.60 & 0.00 & 0.852 \\
10 & 12.50 & 24.70 & 12.50 & 10.60 & 0.00 & 0.852 \\
11 & 16.80 & 17.90 & 12.50 & 10.60 & 0.00 & 0.852 \\
12 & 12.50 & 17.90 & 12.50 & 10.60 & 0.00 & 0.853 \\
13 & 16.80 & 24.70 & 3.10 & 10.60 & 0.00 & 0.793 \\
14 & 12.50 & 24.70 & 3.10 & 10.60 & 0.00 & 0.793 \\
15 & 16.80 & 17.90 & 3.10 & 10.60 & 0.00 & 0.793 \\
16 & 12.50 & 17.90 & 3.10 & 10.60 & 0.00 & 0.796 \\
17 & 16.80 & 24.70 & 12.50 & 17.90 & 0.10 & 1.834 \\
18 & 12.50 & 24.70 & 12.50 & 17.90 & 0.10 & 1.817 \\
19 & 16.80 & 17.90 & 12.50 & 17.90 & 0.10 & 1.421 \\
20 & 12.50 & 17.90 & 12.50 & 17.90 & 0.10 & 1.402 \\
21 & 16.80 & 24.70 & 3.10 & 17.90 & 0.10 & 1.821 \\
22 & 12.50 & 24.70 & 3.10 & 17.90 & 0.10 & 1.804 \\
23 & 16.80 & 17.90 & 3.10 & 17.90 & 0.10 & 1.406 \\
24 & 12.50 & 17.90 & 3.10 & 17.90 & 0.10 & 1.392 \\
25 & 16.80 & 24.70 & 12.50 & 10.60 & 0.10 & 1.714 \\
26 & 12.50 & 24.70 & 12.50 & 10.60 & 0.10 & 1.697 \\
27 & 16.80 & 17.90 & 12.50 & 10.60 & 0.10 & 1.278 \\
28 & 12.50 & 17.90 & 12.50 & 10.60 & 0.10 & 1.260 \\
29 & 16.80 & 24.70 & 3.10 & 10.60 & 0.10 & 1.701 \\
30 & 12.50 & 24.70 & 3.10 & 10.60 & 0.10 & 1.681 \\
31 & 16.80 & 17.90 & 3.10 & 10.60 & 0.10 & 1.267 \\
32 & 12.50 & 17.90 & 3.10 & 10.60 & 0.10 & 1.249 \\
33 & 14.65 & 21.30 & 7.80 & 14.25 & 0.00 & 1.097 \\
34 & 14.65 & 21.30 & 7.80 & 14.25 & 0.04 & 1.364 \\
35 & 14.65 & 21.30 & 7.80 & 14.25 & 0.05 & 1.414 \\
36 & 14.65 & 21.30 & 7.80 & 14.25 & 0.06 & 1.454 \\
37 & 14.65 & 21.30 & 7.80 & 14.25 & 0.10 & 1.535 \\
38 & 12.64 & 18.22 & 3.91 & 11.39 & 0.01 & 0.928 \\
39 & 13.66 & 19.90 & 6.19 & 12.91 & 0.04 & 1.261 \\
40 & 15.14 & 21.96 & 9.26 & 15.14 & 0.07 & 1.561 \\
41 & 16.13 & 23.63 & 10.36 & 16.61 & 0.09 & 1.731 \\
42 & 16.33 & 24.23 & 11.47 & 17.59 & 0.10 & 1.798 \\
\hline & & & & & &
\end{tabular}

The nonlinear-fitting function is used to solve the undetermined coefficients by least squares regression. Results of undetermined coefficients are listed in Table 5. The comparisons of $F_{s}$ in FLAC 3D obtained by the response function are shown in Figure $5 . F_{s}$ obtained from the response surface and that from FLAC 3D agree well. This means that the fitting of the performance function is valid.

Substituting the results of Table 5 into equations (3) and (6)-(9), we obtain the explicit expression of performance function as

$$
\begin{aligned}
M= & \left(14.46171 k_{r}-67.9998 k_{r}^{2}\right)\left(0.350237+0.005312 c_{p}\right. \\
& \left.+0.035093 \varphi_{p}+0.001088 \varphi_{p}^{2}\right) \\
& +\left(1-14.46171 k_{r}+67.9998 k_{r}^{2}\right)\left(0.065479+0.005458 c_{r}\right. \\
& \left.+0.061833 \varphi_{r}+0.00053 \varphi_{r}^{2}\right)-1,
\end{aligned}
$$$$
F_{p}=0.350237+0.005312 c_{p}+0.035093 \varphi_{p}+0.001088 \varphi_{p}^{2}
$$

$F_{r}=0.065479+0.005458 c_{r}+0.061833 \varphi_{r}+0.00053 \varphi_{r}^{2}$,

$w_{1}=14.46171 k_{r}-67.9998 k_{r}^{2}$

$w_{2}=1-14.46171 k_{r}+67.9998 k_{r}^{2}$

4.2.2. Sensitivity of Safety Factor to Variables. The response result of $F_{p}$ induced by $c_{p}$ and $\varphi_{p}$, response result of $F_{r}$ induced by $c_{r}$ and $\varphi_{r}$, and response result of $w_{1}$ and $w_{2}$ induced by $k_{r}$ are shown in Figures 6(a)-6(c), respectively. These results indicate that $\varphi_{p}$ has a greater influence on the peak safety factor $F_{p}$ than $c_{p} ; \varphi_{r}$ has a greater influence on the residual safety factor $F_{r}$ than $c_{r}$. The nonlinear influence of shear strength parameters $\left(c_{p}, \varphi_{p} ; c_{r}, \varphi_{r}\right)$ is not obvious on respective intervals. However, $k_{r}$ greatly affects the weight function $w_{1}$ and $w_{2}$, and the nonlinear influence is obvious even on the small interval $k_{r}=[0,0.1]$.

Sensitivity of safety factor $F_{s}$ to variables is shown in Figure 7. Each interval variable is analyzed with the others fixed at the mean value. Results indicate that all the interval variables have some influence to safety factor $F_{s}$; however, the influence of $c_{p}$ and $c_{r}$ is not so obvious. The sensitivity to interval variables can be ranked as $k_{r}>\varphi_{p}>\varphi_{r}>c_{r}>c_{p}$.

Under the assumptions in Section 2.3, $w_{1}$ and $w_{2}$ are equal to the weight functions to control the contributions of $F_{p}$ and $F_{r}$ to $F_{s}$. That is to say, $k_{r}$ is equal to a weight coefficient to control the contributions of $\left(c_{p}, \varphi_{p} ; c_{r}, \varphi_{r}\right)$ to $F_{s}$. Therefore, the interval response of $F_{s}$ induced by each interval variables under different $k_{r}$ is shown in Figure $8 k_{r}$ values are set to $0.00,0.02,0.04,0.06,0.08$, and 0.10 , respectively. When an interval variable is analyzed, others are 
TABLE 5: Results of undetermined coefficients by regression.

\begin{tabular}{lc}
\hline Coefficient & Value \\
\hline$a_{1}$ & 0.350237 \\
$a_{2}$ & 0.005312 \\
$a_{3}$ & 0.035093 \\
$a_{4}$ & 0.001088 \\
$b_{1}$ & 0.065479 \\
$b_{2}$ & 0.005458 \\
$b_{3}$ & 0.061833 \\
$b_{4}$ & 0.00053 \\
$c_{1}$ & 14.46171 \\
$c_{2}$ & -67.99980 \\
\hline
\end{tabular}

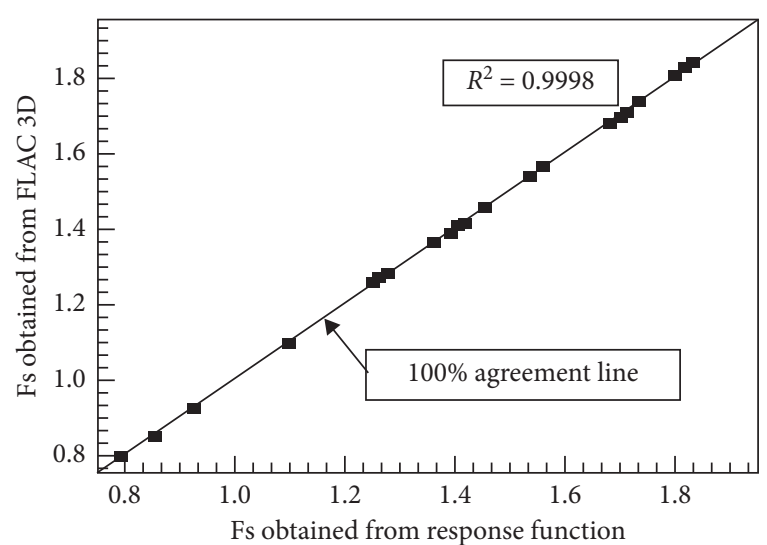

Figure 5: Results of $F_{s}$ comparison between the response surface and FLAC 3D.

fixed at the mean value. Results indicate that, with $k_{r}$ increasing, the interval response of $F_{s}$ induced by $c_{r}$ and $c_{p}$ changes slightly. In detail, the value of $F_{s}$ induced by $c_{r}$ decreases, induced by $\varphi_{p}$ increases. However, with $k_{r}$ increasing, the interval response of $F_{s}$ induced by $\varphi_{r}$ decreases and that induced by $\varphi_{p}$ increases. The average level of interval response of $F_{s}$ increases with the growth of $k_{r}$. Therefore, it is considered that all the interval variables are of great significance to safety factor $F_{s}$, where $k_{r}$ is the most outstanding one.

\subsection{Reliability Analysis}

4.3.1. Results of Reliability. According to the result in equation (14), the monotony of performance function $M$ can be obtained. For $\forall k_{r} \in[0,0.1], w_{1} \in[0,0.7662]$ and $w_{2} \in[0.2338,1]$. For $\forall\left(c_{p}, \varphi_{p}, c_{r}, \varphi_{r}\right)$ on their interval, $F_{p} \in[1.3934,1.9701]$ and $F_{r} \in[0.7974,1.4103]$. For each single interval variable, function $M$ is continuous monotonic. However, $k_{r}$ is at least more than 0.04 in Baishi ancient landslide according to the literature [41]. In fact, the strength of whole slip surface is in residual state when $k_{r} \longrightarrow 0$, which is unreal for an ancient landslide with prolonged dormancy. Therefore, in Baishi ancient landslide, we adopt $k_{r} \in[0.04,0.1]$, and the interval nonprobability reliability is solved as

$$
\begin{aligned}
M^{\min } & =0.0773, \\
M^{\max } & =0.8392, \\
\eta & =\frac{M^{c}}{M^{r}}=\frac{1 / 2\left(M^{\min }+M^{\max }\right)}{1 / 2\left(M^{\max }-M^{\min }\right)} \\
& =\frac{0.5 \times(0.0773+0.8392)}{0.5 \times(0.8392-0,0773)}=1.2029 .
\end{aligned}
$$

Result of $\eta$ indicates that Baishi ancient landslide is reliable and safe $(\eta>1)$ under the natural condition, agreeing well with the actual situation. In fact, the planned highway began the construction several months ago, and this landslide was also safe during the disturbance of construction.

The reliability analysis is also conducted by the traditional probabilistic method to make a comparison. According to the literature [26], $c_{p}, \varphi_{p}, c_{r}, \varphi_{r}$, and $k_{r}$ are considered as random variables. $c_{p}, \varphi_{p}, c_{r}$, and $\varphi_{r}$ are assumed as log-normal distribution, but $k_{r}$ is assumed as beta distribution. Mean values are fixed as the same as the mean of intervals in this paper, and coefficients of variation are chosen from the literature [26]. The probability reliability index is also defined as the minimum distance from the origin point to the failure surface in the standard normal space. Some results are listed in Table 6.

Results in Table 6 indicate that the reliability is greatly influenced by the probability density distribution. The probability reliability index $\eta$ can be little to 0.8364 with nearly $10 \%$ probability of failure. It can be also large to 2.1075 but with nearly $35 \%$ probability of failure. These results cannot be used in landslide engineering. However, bounds of interval variables can well solve this problem. The robustness of interval nonprobability reliability makes it more suitable to evaluate a landslide with the strain-softening behavior when the probability density is unknown.

4.3.2. Sensitivity of Interval Nonprobability Reliability Index on Variables. For each interval variable, $x_{i}=x_{i}^{c}+\delta_{i} x_{i}^{r}$, where $x_{i}^{c}$ is the center value, $x_{i}^{r}$ is the radius of interval and $\delta_{i}=[-1,1] . x_{i}^{c}$ and $x_{i}^{r}$ are the controlling indexes of an interval.

The influence of interval radius to interval nonprobability reliability index $\eta$ is shown in Figure 9. Fix the center value $x_{i}^{c}$ of an interval variable at original value; change the radius $x_{i}^{r}$ from 0 to original maximum radius, presented by axis from 0 to 1 (Figure 9), while other interval variables are set as usual. Results indicate that when the interval radius of $k_{r}$ and $\varphi_{r}$ decreases, $\eta$ significantly improves; the fall of the radius of $c_{p}$ and $c_{r}$ contributes little to the improvement of $\eta$; the drop in radius of $\varphi_{p}$ even makes $\eta$ decrease. Therefore, the influence of variable radius is ranked as follows: $k_{r}>\varphi_{r}>c_{r}>c_{p}>\varphi_{p}$. It is worth noting that decreasing variable radius of $\varphi_{p}$ declines $\eta$ as well. The reason is that, when the radius of $\varphi_{p}$ decreases to $0, \varphi_{p}$ eventually converges to a mean value. It indicates that the center value $x_{i}^{c}$ of interval variable is also of great importance. 


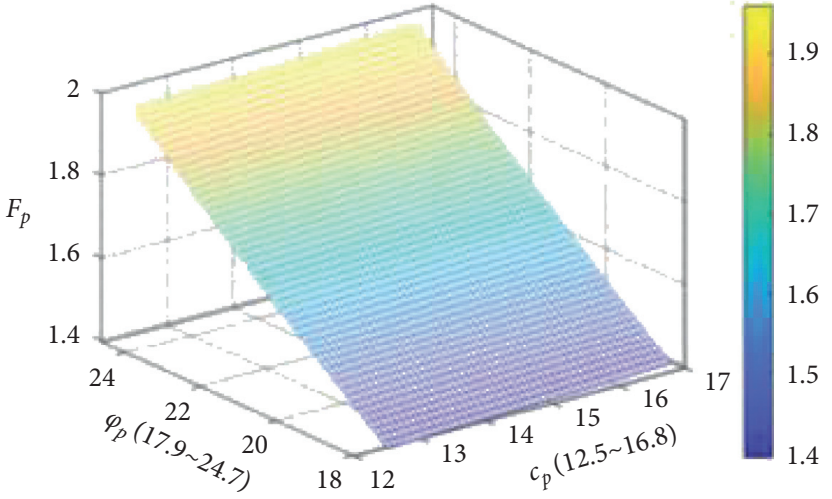

(a)

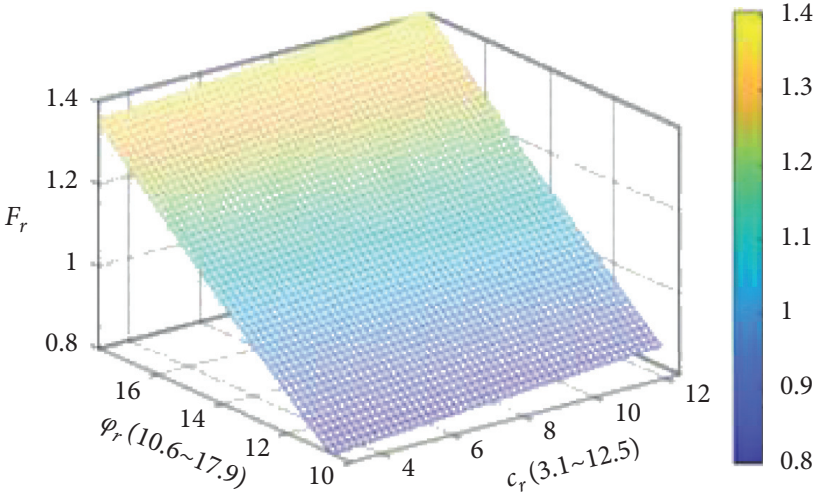

(b)

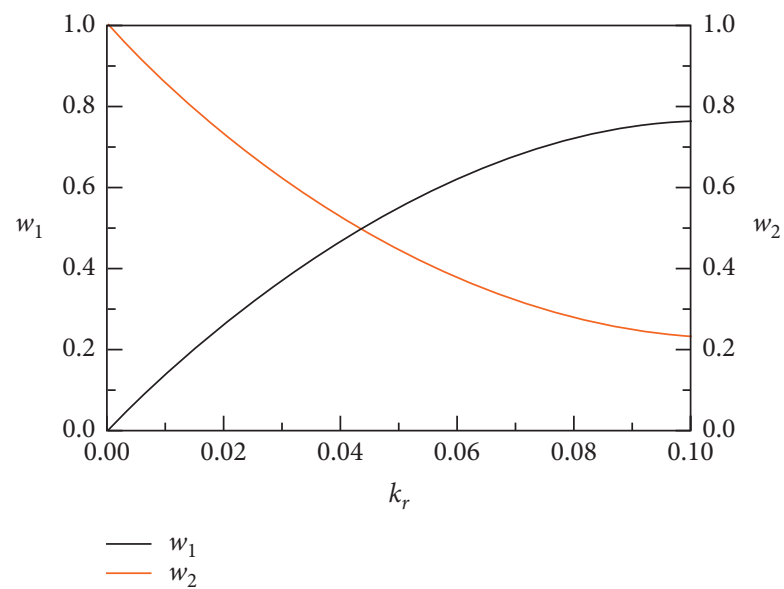

(c)

FiguRE 6: (a) Response result of $F_{p}$ induced by $c_{p}$ and $\varphi_{p}$. (b) Response result of $F_{r}$ induced by $c_{r}$ and $\varphi_{r}$. (c) Response results of $w_{1}$ and $w_{2}$ induced by $k_{r}$.

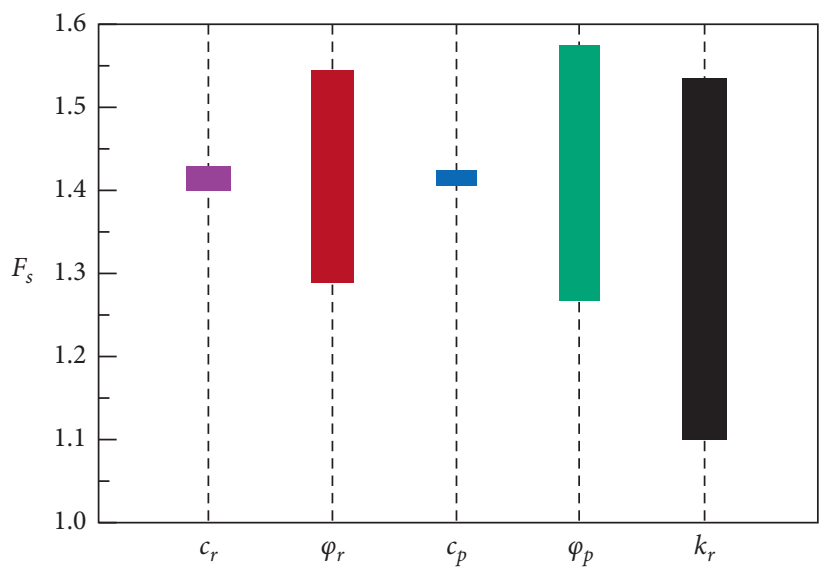

FIgURE 7: Interval response of $F_{s}$ induced by each interval variables.

The influence of interval center value to $\eta$ is shown in Figure 10. The radius $x_{i}^{r}$ of an interval variable is fixed at 0 ; the interval center value changes from minimum to maximum on the interval, presented by axis from -1 to 1 (Figure 10), while other interval variables are set as usual. Results indicate that when the center value of interval variables $k_{r}$ and $\varphi_{r}$ increases, $\eta$ significantly increases. And, the line of $\varphi_{r}$ grows faster. When the center value of interval variables $c_{r}, c_{p}, \varphi_{p}$ increases, the growth of $\eta$ is not so obvious.

The interval response of $\eta$ induced by interval variables $\left(c_{p}, \varphi_{p}, c_{r}, \varphi_{r}\right)$ under different $k_{r}$ is shown in Figure 11. Set $k_{r}$ to $0.00,0.02,0.04,0.06,0.08$, and 0.10 , respectively. The radius $x_{i}^{r}$ of an interval variable is fixed at 0 ; the interval 


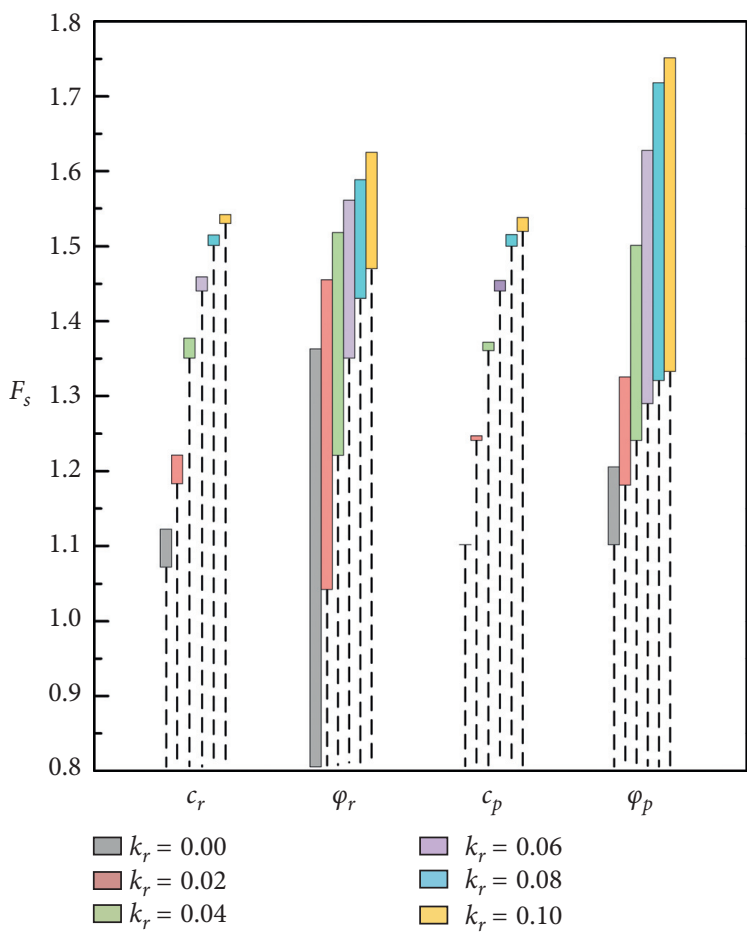

FiguRE 8: Interval response of $F_{s}$ induced by the interval variables $\left(c_{p}, \varphi_{p} ; c_{r}, \varphi_{r}\right)$ under different $k_{r}$ values.

TABLE 6: Results in probabilistic reliability calculations under different variable distributions.

\begin{tabular}{|c|c|c|c|c|c|c|c|c|}
\hline \multirow[b]{2}{*}{$c_{p}$} & \multicolumn{3}{|c|}{$\mathrm{COV}$ of log-normal variables } & \multicolumn{2}{|c|}{$\begin{array}{c}\text { Beta } \\
\text { distribution } \\
\text { parameters }\end{array}$} & \multirow[t]{2}{*}{$p_{f}(\%)$} & \multirow[t]{2}{*}{ PRI- $\eta$} & \multirow[t]{2}{*}{ INPRI- $\eta$} \\
\hline & $c_{r}$ & $\varphi_{p}$ & $\varphi_{r}$ & $q$ & $r$ & & & \\
\hline 0.2 & 0.2 & 5 & 5 & 1 & 6 & 10.85 & 0.9443 & \multirow{6}{*}{1.2029} \\
\hline 0.5 & 0.5 & 10 & 10 & 1 & 6 & 34.76 & 0.8364 & \\
\hline 0.2 & 0.2 & 5 & 5 & 6 & 6 & 10.71 & 1.4016 & \\
\hline 0.5 & 0.5 & 10 & 10 & 6 & 6 & 34.91 & 1.3567 & \\
\hline 0.2 & 0.2 & 5 & 5 & 6 & 2 & 11.36 & 2.1075 & \\
\hline 0.5 & 0.5 & 10 & 10 & 6 & 2 & 35.75 & 1.7697 & \\
\hline
\end{tabular}

Note: COV: coefficient of variation, $q$ and $r$ are the parameters describing the probability density distribution, $p_{f}$ is the probability of failure, PRI- $\eta$ is the probability reliability index, and INPRI- $\eta$ is interval nonprobability of failure. More details are shown in the literature [26].

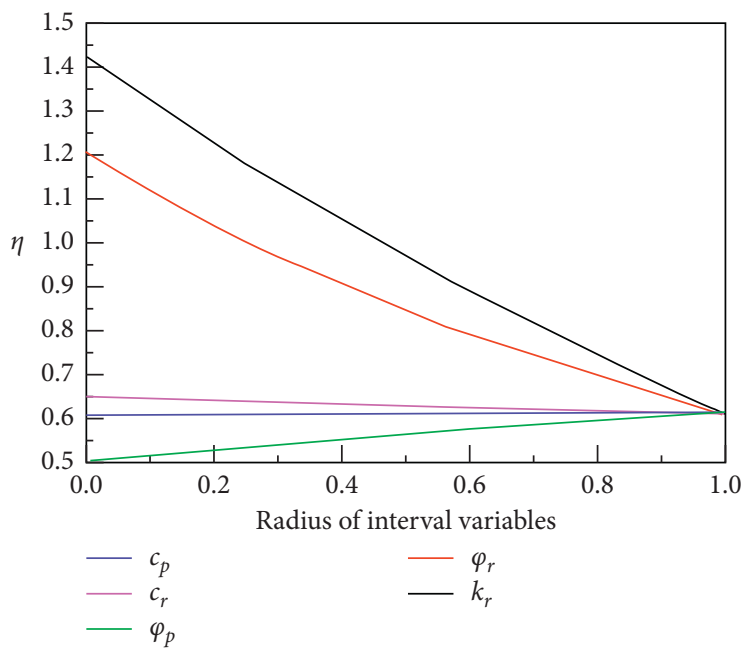

FIGURE 9: Results of reliability index $\eta$ influenced by the interval radius of five variables. 


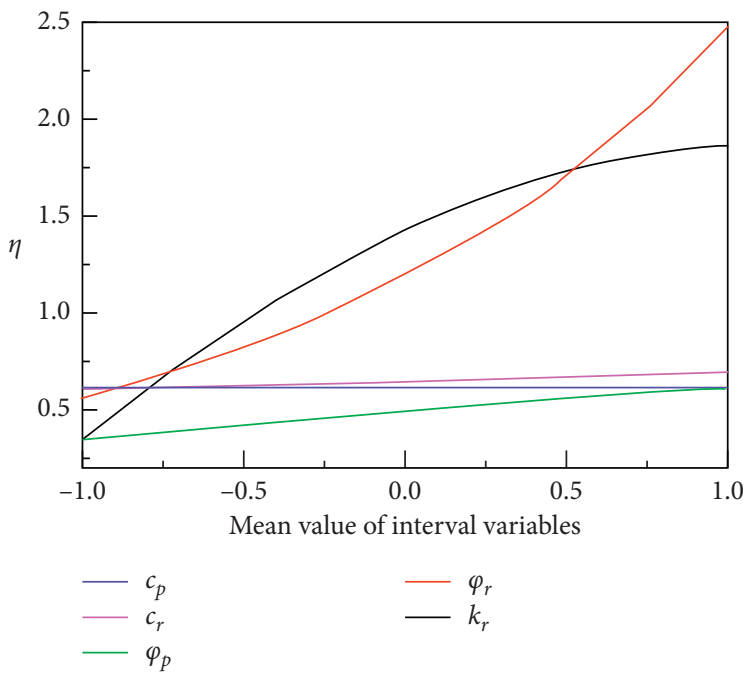

FIGURE 10: Results of reliability index $\eta$ influenced by the interval center of five variables.

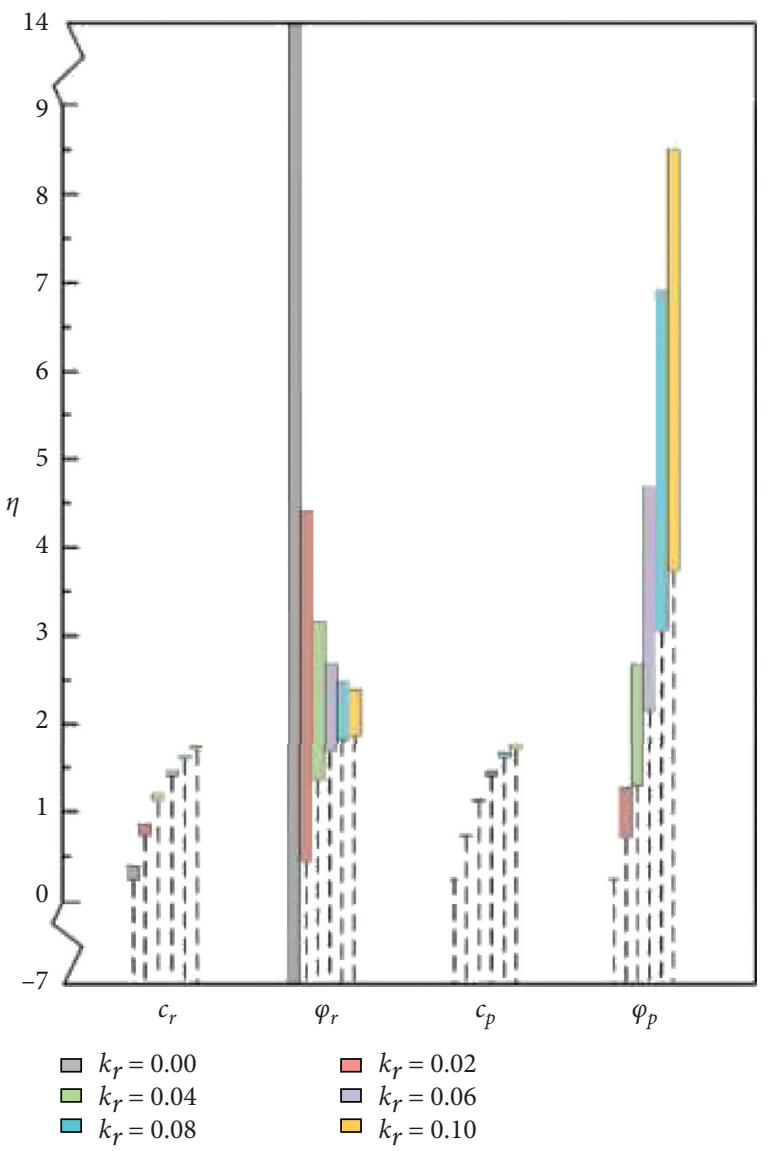

FIGURE 11: Interval response of reliability index $\eta$ induced by interval variables $\left(c_{p}, \varphi_{p}, c_{r}, \varphi_{r}\right)$ under different $k_{r}$ values.

center value is changed from the minimum value to the maximum on the interval, while other interval variables are set as usual. Results in Figure 11 indicate that, with $k_{r}$ increasing, the interval response of $\eta$ induced by $c_{r}$ and $c_{p}$ changes slightly. In detail, the value of $\eta$ induced by $c_{r}$ decreases and that induced by $\varphi_{p}$ increases. However, with $k_{r}$ increasing, the interval response of $\eta$ induced by $\varphi_{r}$ quickly decreases and that induced by $\varphi_{p}$ quickly increases. In summary, both the center value and range of all interval variables are important to $\eta$. The $k_{r}$ is the most significant factor which should be preferentially determined.

\section{Conclusions}

In the present study, an interval nonprobability reliability analysis framework combined with numerical strain-softening constitutive relations was established to evaluate the reliability of Baishi ancient landslide. The main conclusions can be drawn as follows:

(1) The uncertainties of geomaterial properties significantly affect the stability evaluation of the ancient landslide. To correctly and effectively consider these uncertainties when data are scarce, an interval nonprobability reliability analysis framework combined with numerical strain-softening constitutive relations is established.

(2) The proposed reliability analysis method is verified by Baishi ancient landslide as a case study. Uncertain parameters $\left(c_{p}, \varphi_{p}, c_{r}, \varphi_{r}\right.$, and $\left.k_{r}\right)$ in the strainsoftening numerical constitutive relation are set as interval variables. The interval nonprobability reliability index $\eta$ is defined as the minimum distance from the origin point to the failure surface in the standard normal space. This index is used to describe the ability of a system to tolerate the variation of uncertain parameters.

(3) The interval nonprobability reliability index $\eta$ of Baishi is $1.2029(>1)$, indicating that Baishi ancient landslide is safe under the nature condition. The results calculated by the proposed method agree with the reality. However, the reliability index $\eta$ in the probability method ranges greatly; Baishi ancient landslide holds a 
$35 \%$ probability of failure. Therefore, the interval nonprobability method is more suitable.

(4) The sensitivity analysis indicates that $k_{r}$ is the most significant variable controlling both safety factor $F_{s}$ and interval nonprobability reliability index $\eta$. In addition, $k_{r}$ is equivalent to a weight coefficient that can affect the influence of $\left(c_{r}, \varphi_{r}\right)$ and $\left(c_{p}, \varphi_{p}\right)$. When $k_{r}$ increases, the influence of $\left(c_{r}, \varphi_{r}\right)$ decreases but that of $\left(c_{p}, \varphi_{p}\right)$ increases.

(5) Interval nonprobability reliability method combined with numerical strain-softening constitutive relation can accurately present the relation of parameters between peak and residual strength with a few data and obtain robust results. It provides a great complement for traditional probabilistic methods.

\section{Data Availability}

The data used to support the findings of this study are included within the article.

\section{Conflicts of Interest}

The authors declare that there are no conflicts of interest regarding the publication of this paper.

\section{Acknowledgments}

This work was supported by the National Basic Research Program of China (2015CB060200), the National Natural Science Foundation of China (41772313), Hunan Science and Technology Planning Project (2019RS3001), and the Graduated Students' Research and Innovation Fund Project of Central South University (2019zzts987).

\section{References}

[1] Z. Zhou, X. Cai, X. Li, W. Cao, and X. Du, "Dynamic response and energy evolution of sandstone under coupled static-dynamic compression: insights from experimental study into deep rock engineering applications," Rock Mechanics and Rock Engineering, vol. 53, no. 3, pp. 1305-1331, 2020.

[2] X. Cai, Z. L. Zhou, L. H. Tan, H. Z. Zang, and Z. Y. Song, "Fracture behavior and damage mechanisms of sandstone subjected to wetting-drying cycles," Engineering Fracture Mechanics, vol. 234, Article ID 107109, 2020.

[3] X. Cai, Z. L. Zhou, and X. M. Du, "Water-induced variations in dynamic behavior and failure characteristics of sandstone subjected to simulated geo-stress," Rock Mechanics and Rock Engineering, vol. 130, Article ID 104339, 2020.

[4] Z. Zhou, H. Wang, X. Cai, L. Chen, Y. E, and R. Cheng, "Damage evolution and failure behavior of post-mainshock damaged rocks under aftershock effects," Energies, vol. 12, no. 23, p. 4429, 2019.

[5] D. Ma, H. Duan, X. Li, Z. Li, Z. Zhou, and T. Li, "Effects of seepage-induced erosion on nonlinear hydraulic properties of broken red sandstones," Tunnelling and Underground Space Technology, vol. 91, Article ID 102993, 2019.

[6] T. Bong and Y. Son, "Probabilistic analysis of weathered soil slope in South Korea," Advances in Civil Engineering, vol. 2018, Article ID 2120854, 12 pages, 2018.
[7] Y. Li, H. Zhang, X. Liu, G. Liu, D. Hu, and X. Meng, "Timevarying compressive strength model of aeolian sand concrete considering the harmful pore ratio variation and heterogeneous nucleation effect," Advances in Civil Engineering, vol. 2019, Article ID 8267601, 15 pages, 2019.

[8] E. Conte, A. Donato, L. Pugliese, and A. Troncone, "Analysis of the maierato landslide (Calabria, southern Italy)," Landslides, vol. 15, no. 10, pp. 1935-1950, 2018.

[9] Q.-j. Pan, X.-r. Qu, and X. Wang, "Probabilistic seismic stability of three-dimensional slopes by pseudo-dynamic approach," Journal of Central South University, vol. 26, no. 7, pp. 1687-1695, 2019.

[10] E. Shamekhi and D. D. Tannant, "Probabilistic assessment of rock slope stability using response surfaces determined from finite element models of geometric realizations," Computers and Geotechnics, vol. 69, pp. 70-81, 2015.

[11] D. V. Griffiths, J. Huang, and G. A. Fenton, "Probabilistic infinite slope analysis," Computers and Geotechnics, vol. 38, no. 4, pp. 577-584, 2011.

[12] X. Wang, H. Wang, and R. Y. Liang, "A method for slope stability analysis considering subsurface stratigraphic uncertainty," Landslides, vol. 15, no. 5, pp. 925-936, 2018.

[13] Z.-P. Deng, D.-Q. Li, X.-H. Qi, Z.-J. Cao, and K.-K. Phoon, "Reliability evaluation of slope considering geological uncertainty and inherent variability of soil parameters," Computers and Geotechnics, vol. 92, pp. 121-131, 2017.

[14] K. Terzaghi, R. B. Peck, and G. Mesri, "Soil Mechanics in Engineering Practice", John Wiley \& Sons, Hoboken, NJ, USA, 3rd edition, 1996.

[15] S.-1. Zhang, Z.-h. Zhu, S.-c. Qi, Y.-x. Hu, Q. Du, and J.-w. Zhou, "Deformation process and mechanism analyses for a planar sliding in the Mayanpo massive bedding rock slope at the Xiangjiaba hydropower station," Landslides, vol. 15, no. 10, pp. 2061-2073, 2018.

[16] Y. Zhao, X.-p. Zhou, and Q.-h. Qian, "Progressive failure processes of reinforced slopes based on general particle dynamic method," Journal of Central South University, vol. 22, no. 10, pp. 4049-4055, 2015.

[17] G. Zhang and L. Wang, "Stability analysis of strain-softening slope reinforced with stabilizing piles," Journal of Geotechnical and Geoenvironmental Engineering, vol. 136, no. 11, pp. 1578-1582, 2010.

[18] X.-r. Wang, Q.-g. Rong, S.-1. Sun, and H. Wang, "Stability analysis of slope in strain-softening soils using local arc-length solution scheme," Journal of Mountain Science, vol. 14, no. 1, pp. 175-187, 2017.

[19] L. Zhao, S. Zuo, D. Deng, Z. Han, and B. Zhao, "Development mechanism for the landslide at Xinlu village, Chongqing, China," Landslides, vol. 15, no. 10, pp. 2075-2081, 2018.

[20] K. Terzaghi and R. B. Peck, "Soil Mechanics in Engineering Practice”, Wiley, New York, NY, USA, 1948.

[21] A. W. Bishop, "The influence of progressive failure on the choice of the method of stability analysis," Géotechnique, vol. 21, no. 2, pp. 168-172, 1971.

[22] A. W. Skempton, "Long-term stability of clay slopes," Géotechnique, vol. 14, no. 2, pp. 77-102, 1964.

[23] D. A. Grivas and R. N. Chowdhury, "Probabilistic $\varphi=0$ stability analysis in strain-softening soil," Structural Safety, vol. 1, no. 3, pp. 199-210, 1982.

[24] R. N. Chowdhury, W. H. Tang, and I. Sidi, "Reliability model of progressive slope failure," Géotechnique, vol. 37, no. 4, pp. 467-481, 1987.

[25] S. Metya, G. Bhattacharya, and R. Chowdhury, "Reliability analysis of slopes in strain-softening soils considering critical 
slip surfaces," Innovative Infrastructure Solutions, vol. 1, no. 1, pp. 1-7, 2016.

[26] G. Bhattacharya, R. Chowdhury, and S. Metya, "Residual factor as a variable in slope reliability analysis," Bulletin of Engineering Geology and the Environment, vol. 78, no. 1, pp. 147-166, 2019.

[27] K. Karuna and C. S. Manohar, "Inverse problems in structural safety analysis with combined probabilistic and non-probabilistic uncertainty models," Engineering Structures, vol. 150, pp. 166-175, 2017.

[28] Y. Wang, P. Zhang, and G. Qin, "Non-probabilistic timedependent reliability analysis for suspended pipeline with corrosion defects based on interval model," Process Safety and Environmental Protection, vol. 124, pp. 290-298, 2019.

[29] X.-X. Liu and I. Elishakoff, "A combined importance sampling and active learning Kriging reliability method for small failure probability with random and correlated interval variables," Structural Safety, vol. 82, Article ID 101875, 2020.

[30] L. Dong, D. Sun, X. Li, and Z. Zhou, "Interval non-probabilistic reliability of a surrounding jointed rockmass in underground engineering: a case study," IEEE Access, vol. 5, pp. 18804-18817, 2017.

[31] L. Dong, D. Sun, and X. Li, "Theoretical and case studies of interval nonprobabilistic reliability for tailing dam stability," Geofluids, vol. 2017, Article ID 8745894, 11 pages, 2017.

[32] H. Su, J. Li, Z. Guo, and Z. Wen, "Nonprobabilistic reliability evaluation for in-service gravity dam undergoing structural reinforcement," IEEE Transactions on Reliability, vol. 67, no. 3, pp. 970-986, 2018.

[33] E. Conte, F. Silvestri, and A. Troncone, "Stability analysis of slopes in soils with strain-softening behaviour," Computers and Geotechnics, vol. 37, no. 5, pp. 710-722, 2010.

[34] Z. Nie, Z. Zhang, and H. Zheng, "Slope stability analysis using convergent strength reduction method," Engineering Analysis with Boundary Elements, vol. 108, pp. 402-410, 2019.

[35] Y. Chen and H. Lin, "Consistency analysis of Hoek-Brown and equivalent Mohr-coulomb parameters in calculating slope safety factor," Bulletin of Engineering Geology and the Environment, vol. 78, no. 6, pp. 4349-4361, 2019.

[36] K. Zhang, P. Cao, and R. Bao, "Progressive failure analysis of slope with strain-softening behaviour based on strength reduction method," Journal of Zhejiang University-Science A (Applied Physics \& Engineering), vol. 14, no. 2, pp. 26-34, 2013.

[37] G.-H. Yang, Z.-H. Zhong, X.-D. Fu, Y.-C. Zhang, Y. Wen, and M.-F. Zhang, "Slope analysis based on local strength reduction method and variable-modulus elasto-plastic model," Journal of Central South University, vol. 21, no. 5, pp. 2041-2050, 2014.

[38] X.-P. Zhou and X.-C. Huang, "Reliability analysis of slopes using UD-based response surface methods combined with LASSO," Engineering Geology, vol. 233, pp. 111-123, 2018.

[39] D.-Q. Li, D. Zheng, Z.-J. Cao, X.-S. Tang, and K.-K. Phoon, "Response surface methods for slope reliability analysis: review and comparison," Engineering Geology, vol. 203, pp. 314, 2016.

[40] H. Basahel and H. Mitri, "Probabilistic assessment of rock slopes stability using the response surface approach-a case study," International Journal of Mining Science and Technology, vol. 29, no. 3, pp. 357-370, 2019.

[41] D. R. Bhat, R. Yatabe, and N. P. Bhandary, "Study of preexisting shear surfaces of reactivated landslides from a strength recovery perspective," Journal of Asian Earth Sciences, vol. 77, pp. 243-253, 2013. 